\title{
A combined salt-hard templating approach for synthesis of multi-modal porous carbons used for probing the simultaneous effects of porosity and electrode engineering on EDLC performance
}

Nidhi Bhandari, ${ }^{\sharp a}$ Rubal Dua, ${ }^{\ddagger b}$ Luis Estevez, ${ }^{a}$ Ritu Sahore, ${ }^{a}$ Emmanuel P. Giannelis ${ }^{* a}$

${ }^{a}$ Department of Materials Science and Engineering, Cornell University, Ithaca, NY 14853 (USA)

${ }^{b}$ Water Desalination and Reuse Center, Biological and Environmental Science and Engineering Division, King Abdullah University of Science and Technology (KAUST), Thuwal, Kingdom of Saudi Arabia, 23955-6900

${ }^{*}$ These authors contributed equally to this work

*Address correspondence to epg2@cornell.edu 


\begin{abstract}
A new approach, based on a combination of salt and hard templating for producing multimodal porous carbons is demonstrated. The hard template, silica nanoparticles, generate mesopores $(\sim 22 \mathrm{~nm})$, and in some cases borderline-macropores $(\sim 64 \mathrm{~nm})$, resulting in high pore

volume $\left(\sim 3.9 \mathrm{~cm}^{3} / \mathrm{g}\right)$ while the salt template, zinc chloride, generates borderline-mesopores $(\sim 2$ $\mathrm{nm})$, thus imparting high surface area $\left(\sim 2100 \mathrm{~m}^{2} / \mathrm{g}\right)$. The versatility of the proposed synthesis technique is demonstrated using: i) dual salt templates with hard template resulting in magnetic, nanostructured-clay embedded ( 27\% clay content), high surface area $\left(\sim 1527 \mathrm{~m}^{2} / \mathrm{g}\right)$ bimodal carbons ( 2 and $70 \mathrm{~nm}$ pores), (ii) multiple hard templates with salt template resulting in trimodal carbons $\left(\sim 2,12\right.$ and $28 \mathrm{~nm}$ pores), (iii) low temperature $\left(450{ }^{\circ} \mathrm{C}\right)$ synthesis of bimodal carbons afforded by the presence of hygroscopic salt template, (iv) easy coupling with physical activation approaches. A selected set of thus synthesized carbons were used to evaluate, for the first time, the simultaneous effects of carbon porosity and pressure applied during electrode fabrication on EDLC performance. Electrode pressing was found to be more favorable for carbons containing hard-templated mesopores ( $~ 87 \%$ capacitance retention at current density of $40 \mathrm{~A} / \mathrm{g})$ as compared to those without ( $\sim 54 \%$ capacitance retention).
\end{abstract}

\title{
1. Introduction
}

Recently, there has been considerable attention devoted towards understanding and tailoring the material properties [1-10] and electrode processing conditions [11-18] to enhance the performance of porous carbons used as electrode materials for supercapacitors. Among the various carbon material properties, the pore size distribution has been shown to play a very significant role $[1-4,6-10]$. Hierarchically porous carbons comprised of interconnected 
macropores $(>50 \mathrm{~nm})$, mesopores $(2-50 \mathrm{~nm})$ and micropores $(<2 \mathrm{~nm})$, have appeared as promising candidates for electrode materials for supercapacitors [5-9, 19-23]. In general, the micropores provide sites for electrosorption, whereas the mesopores and macropores act as electrolyte reservoirs as well as provide pathways for electrolyte transport [9, 24]. Among the various reported studies aimed at probing the effect of carbon porosity on its supercapacitor performance, there appears to be a consensus on the favorable effect of microporosity on electrical double-layer capacitance (EDLC) performance, with higher microporosity leading to higher surface area and thus higher EDLC capacitance, as long as the pores are accessible to the electrolyte ions [2]. However, the favorable effect of mesoporosity continues to be debated. Some studies indicate that the presence of mesoporosity leads to enhanced capacitance retention at higher current densities, but other studies have suggested otherwise [1, 3, 25-27].

The electrode processing conditions have also been shown to have a significant effect on the EDLC performance $[11-18,28]$. For example, forced electrolyte infiltration was found to overcome, to some extent, the capacitance retention problem at high current densities associated with primarily microporous carbons [28]. Similarly, applying pressure and forcing the electrolyte into the pores was also found to play a favorable role in enhancing the capacitive performance and lowering IR drop, with the effect of applied pressure being different for different size electrolyte ions $[11,12]$. On the other hand, Ruoff et. al. reported that electrode compression led to an enhanced equivalent series resistance and low EDLC performance (on gravimetric basis), which was ascribed to the loss of a fraction of mesopores in the electrode [18]. In another study, application of pressure during electrode preparation was found to have no effect on the capacitance, while resulting in reduced ohmic drop [13]. Based on the above, there is not a 
consensus in the literature on the effect of application of pressure during electrode fabrication on the EDLC performance. Moreover, most of the studies aimed at understanding the effects of carbon porosity and electrode fabrication on EDLC performance, have been carried out independently. To the best of our knowledge, there are no studies exploring the effects of both carbon porosity and electrode processing conditions simultaneously. In fact, probing the effect of carbon porosity while simultaneously exploring the wide electrode fabrication parameter space, could help shed light in understanding the sometimes contradictory experimental findings reported in the literature.

In this study, we investigate for the first time, the simultaneous effects of carbon porosity and electrode engineering on EDLC performance. To explore the effects of different levels of porosity, four different sets of porous carbons produced using a newly developed technique were tested. Specifically, (i) micropore, (ii) mesopore, (iii) micropore-mesopore, and (iv) microporemacropore dominated carbons were tested and evaluated. In addition, for each carbon, the EDLC performance was measured as a function of increasing pressure applied during electrode manufacturing.

Multi-modal porous carbons have been gaining recently a lot of attention as high performance materials for supercapacitors and other fields including batteries, water purification, $\mathrm{CO}_{2}$ capture, sensors, fuel cells, and hydrogen storage [5, 19, 20, 29-38]. A significant effort has been devoted towards developing efficient synthesis approaches for producing hierarchically porous carbons $[5,20,29,30,39-43]$. The most commonly used methods for producing multimodal porous carbons usually involve two steps: (1) synthesis of a mesopore/macropore 
dominated carbon (through either hard [44] or soft templating or sol-gel) and (2) introduction of microporosity through a second step of activation (either physical or chemical activation) $[5,19$, 20, 45-49]. Although, such techniques can ensure a tight control on porosity at different levels, they often add complexity and make the synthesis highly energy intensive. For practical applications a simple, one step approach for synthesis is highly desirable [29, 30, 39, 50-52].

Recently, salt templating, has emerged as a highly simple and sustainable technique for producing functional porous carbons [53-57]. Salt templating involves the carbonization of a carbon precursor around molten salt at an elevated temperature. However, the technique mainly results in the generation of micropores and some small mesopores, with the pores generated after washing the salt nano-clusters [53]. Herein, we demonstrate a new approach, based on a combination of salt templating and hard templating, for producing high surface area multi-modal porous carbons. The approach involves mixing a solution of an inorganic salt $\left(\mathrm{ZnCl}_{2}\right)$ with a carbon precursor (glucose) and an inorganic hard template (colloidal silica) suspension, followed by vacuum assisted drying and carbonization. The salt $\left(\mathrm{ZnCl}_{2}\right)$ initially melts during carbonization with the glucose precursor forming a carbon matrix around the molten $\mathrm{ZnCl}_{2}$ nanopools, which eventually boil off during carbonization at elevated temperature (1000 $\left.{ }^{\circ} \mathrm{C}\right)$, generating micropores and small mesopores. On the other hand, the removal of colloidal silica through etching with $\mathrm{NaOH}$ generates the mesopores. Different size mesopores, macropores and even tri-modal porous carbons can be generated by using colloidal silica of different sizes and combinations thereof. By using a mixture of two salts, we also demonstrate that the technique can be used for the synthesis of a nanostructured clay embedded, high surface area multi-modal porous carbon. Also, a combined technique involving salt templating-hard templating-physical 
activation, is also demonstrated for the production of very high surface area $\left(\sim 2500 \mathrm{~m}^{2} / \mathrm{g}\right)$ multi-

modal porous carbons. While we have focused here on the effect of porosity on EDLC performance, the inherent flexibility of the synthesis can provide a family of carbons with tailored porosity potentially suitable for specific applications in many energy fields and beyond.

\section{Experimental}

\subsection{Material Synthesis}

For easy reference the overall synthesis approach is schematically depicted in Figure 1. In a typical synthesis, $10 \mathrm{~g}$ of a $30 \mathrm{wt} \%$ suspension of $22 \mathrm{~nm}$ colloidal silica and $3 \mathrm{~g}$ of glucose $\mathrm{D}$ are mixed in a plastic centrifuge tube. Then $6 \mathrm{~g}$ of $\mathrm{ZnCl}_{2}$ salt dissolved in $6 \mathrm{~mL}$ of MilliQ Water is added to the solution and shaken well. After mixing, the sample is vacuum dried until completely dry. The glucose-silica- $\mathrm{ZnCl}_{2}$ composite is then pyrolyzed at $1000{ }^{\circ} \mathrm{C}$, at a ramp rate of $3{ }^{\circ} \mathrm{C} \mathrm{min}^{-1}$ for a dwell time of $2 \mathrm{~h}$ under nitrogen. During the course of pyrolysis, $\mathrm{ZnCl}_{2}$ acts as an in-situ nano-template finally boiling off and leaving behind secondary micropores and small size mesopores. The obtained carbon-silica composite is then stirred first in a $3 \mathrm{M} \mathrm{NaOH}$ solution at room temperature for 4 hours and then the mixture is kept at $95{ }^{\circ} \mathrm{C}$ for 24 hours in an autoclave, to etch out the silica. The sample is finally washed with copious amounts of deionized water and dried at $130{ }^{\circ} \mathrm{C}$ for at least 12 hours before use. For convenience, the samples are denoted by PC $x-y-z$, where PC stands for porous carbon, $x$ represents the average colloidal silica size $(\mathrm{nm})$ and $y(=0$ or 1$)$ represents the mass ratio of silica to glucose in the original suspension, and $z(=0$ or 2$)$ represents the mass ratio of $\mathrm{ZnCl}_{2}$ to glucose. For the purposes of this study, five different carbons were synthesized and tested: (i) PC produced by salt templating alone: PC 0-02, (ii) PCs produced by only hard templating alone: PC 4-1-0, PC 22-1-0, (iii) PCs produced by 
combined salt templating-hard templating: PC 4-1-2, PC 22-1-2. Commercially available colloidal silica suspensions in water with different average size silica: $4 \mathrm{~nm}(15 \mathrm{wt} \%$, Alfa Aesar), $22 \mathrm{~nm}$ (40 wt\%, Ludox TM-40) were used as received.

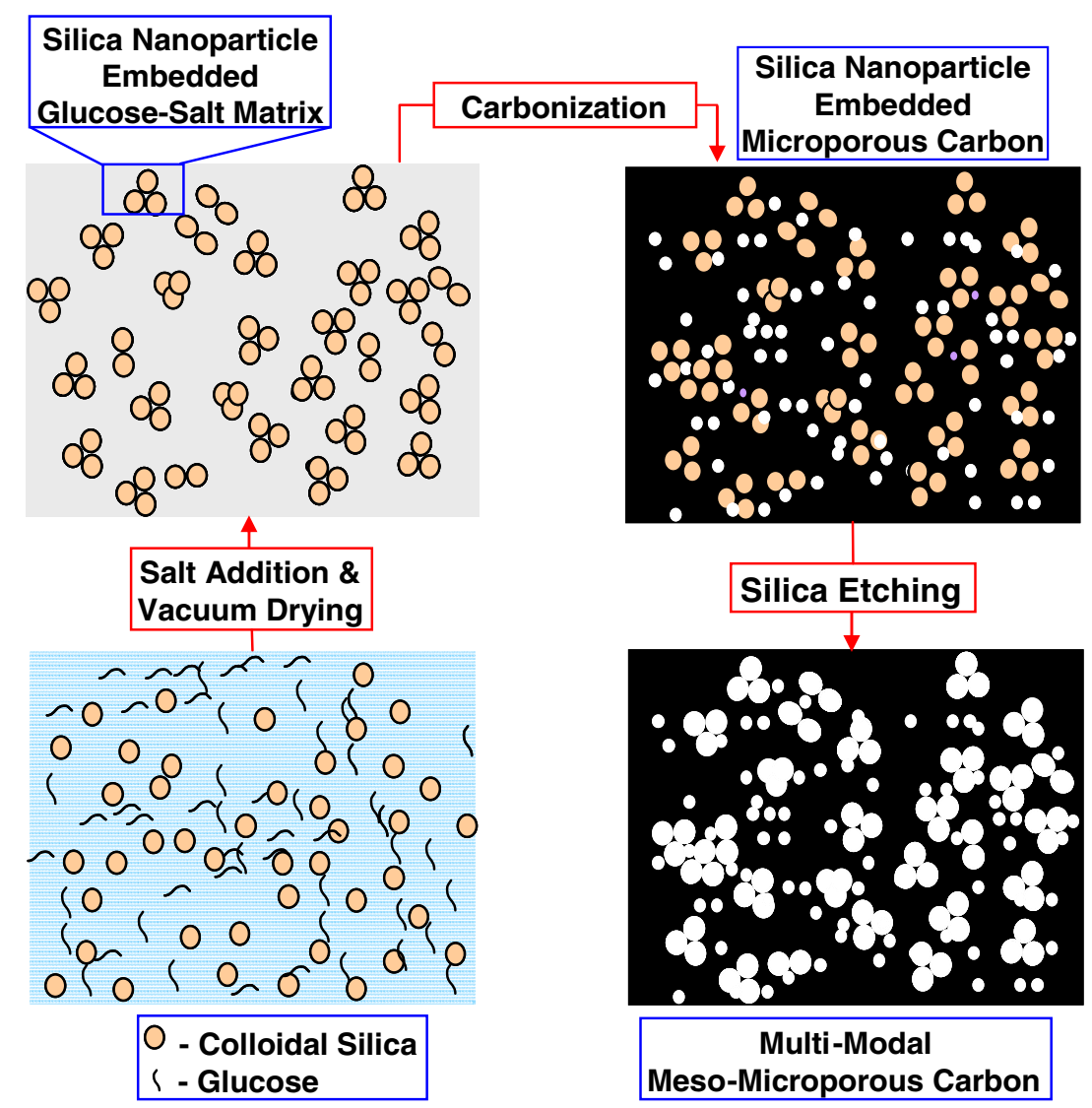

Figure 1. Schematic showing the basic steps involved in the carbon synthesis. The four steps shown clockwise from bottom left are: (1) preparing a glucose-colloidal silica aqueous suspension, (2a) salt addition $\left(\mathrm{ZnCl}_{2}\right)$ to the glucose-silica suspension, which results in controlled aggregation of silica nanoparticles, (2b) vacuum drying resulting in the formation of silica nanoclusters embedded in the glucose-salt matrix, (3) carbonization yielding micropores from boiling of $\mathrm{ZnCl}_{2}$ nano-pools, and (4) silica etching to produce mesopores. For simplification the pores are not shown as interconnected.

For carbon materials produced through the combined salt templating-hard templatingphysical activation procedure, the synthesis procedure is exactly the same as described previously, except for the carbonization at $1000{ }^{\circ} \mathrm{C}$, the inert nitrogen gas is replaced with $\mathrm{CO}_{2}$. A low energy intensity synthesis was also explored, whereby the glucose-silica-salt mixture is 
carbonized at $450{ }^{\circ} \mathrm{C}$ at a ramp rate of $3{ }^{\circ} \mathrm{C} \min ^{-1}$ for a dwell time of $2 \mathrm{~h}$ under nitrogen. The resulting carbon-silica-salt composite is then treated with $1 \mathrm{M} \mathrm{HCl}$ at $85^{\circ} \mathrm{C}$ for 4 hours to etch out the $\mathrm{ZnCl}_{2}$ salt, followed by washing with copious amounts of MilliQ water. The silica nanoparticles are etched out using the same procedure as described above. Finally, porous carbons using a multi salt mixture were also demonstrated. In this synthesis, first a solution of glucose-colloidal silica- $\mathrm{ZnCl}_{2}$ is obtained as described above. Then $1 \mathrm{~g}$ of cobalt nitrate hexahydrate solution (dissolved in $2 \mathrm{~mL}$ MilliQ water) was added to the glucose-colloidal silica$\mathrm{ZnCl}_{2}$ solution, mixed well and vacuum dried. The dried glucose-silica- $\mathrm{ZnCl}_{2}-\mathrm{Co}\left(\mathrm{NO}_{3}\right)_{2}$ composite was then carbonized at $1000{ }^{\circ} \mathrm{C}$ at a ramp rate of $3{ }^{\circ} \mathrm{C} \mathrm{min}{ }^{-1}$ for a dwell time of $2 \mathrm{~h}$ under nitrogen. The obtained carbon-silica-cobalt composite was immersed in $\mathrm{NaOH}$ to remove the silica template. The etched out silica monomers/oligomers react with the embedded cobalt nanoparticles resulting in the formation of cobalt phyllosilicates embedded within the multimodal porous carbon. The nanostructured cobalt phyllosilicates can further be etched out by using $1 \mathrm{M} \mathrm{HCl}$ solution at $85^{\circ} \mathrm{C}$ for 24 hours.

\subsection{Material Characterization}

\subsubsection{Surface area and pore size measurement}

Nitrogen adsorption-desorption tests were carried out at $77 \mathrm{~K}$ using a Micromeritics TriStar II 3020 analyzer. Prior to gas adsorption, the samples were degassed at $180{ }^{\circ} \mathrm{C}$ under $\mathrm{N}_{2}$ for at least 12 hours. The specific surface area was calculated using the Brumauer-Emmett-Teller (BET) method. The pore volume was estimated from single point adsorption at a relative pressure of 0.994 . The pore diameter was determined from the adsorption curve, according to the Barrett-Joyner-Halanda (BJH) method.

\subsubsection{Transmission Electron Microscopy (TEM)}


TEM specimen was prepared by dispersing the carbon powders in ethanol and dropping the resulting suspension onto a 400-mash holey carbon-coated copper grid. Bright-field TEM and high-angle-annular-dark-field (HAADF) scanning (S)TEM images were carried out on FEI Titan ST electron microscope $(\mathrm{Cs}=1.2 \mathrm{~mm} ; \mathrm{Cc}=1.5 \mathrm{~mm} ; 300 \mathrm{kV})$. EDX spectra were collected under STEM mode. The probe size of the microscope was approximately $2.0 \AA$ for STEM imaging and EDX analysis. Energy-filtered transmission electron microscopy (EF-TEM) mapping, energy dispersive X-ray spectroscopy (EDX) mapping, and electron energy loss spectroscopy (EELS) mapping were performed on the same microscope equipped with a GIF system operated at $300 \mathrm{kV}$.

\subsubsection{Electrode preparation and electrochemical characterization}

For electrode preparation, the PCs were first ground using a mortar and pestle. Then 92.5 $\mathrm{wt} \%$ of PC and $7.5 \mathrm{wt} \%$ polytetrafluoroethylene (PTFE) (60 wt\% PTFE obtained from Sigma Aldrich) were mixed in ethanol to form a slurry. The PC-PTFE-ethanol slurry was sonicated for $\sim 30$ minutes and then dried by placing in an oven at $80{ }^{\circ} \mathrm{C}$ for an hour to obtain a dough-like paste. The paste was then rolled into a film $\left(\sim 2 \mathrm{mg} / \mathrm{cm}^{2}\right.$ of active carbon material) and then pressed onto a stainless steel mesh (Alfa Aesar) at a pressure of 1bar, using a hydraulic press.

Electrochemical performance and galvanostatic charge-discharge (GCD) measurements were carried out at room temperature using a two electrode configuration at different current densities ( $\mathrm{I} / 2 \mathrm{~m}$, where $m$ is the mass of a single electrode), with $1 \mathrm{M} \mathrm{H}_{2} \mathrm{SO}_{4}$ as the electrolyte in the potential range between $0-1 \mathrm{~V}$. The effect of pressure (applied using a hydraulic press, in line with Masarapu et al. [11] defined as force applied using the hydraulic press divided by the plate area dimensions) on supercapacitor performance was measured by successively pressing the 
electrodes at increasing pressure values under three different conditions- (i) in the presence of electrolyte soaked cotton, (ii) in the presence of MilliQ water soaked cotton, (iii) in the presence of dry cotton. The pressing was done in between successive EDLC measurements, using a cotton square $(\sim 1 \mathrm{~cm}$ by $1.5 \mathrm{~cm})$ placed in between the two electrodes, with the carbon film side facing the cotton square. The specific capacitance, energy density, power density, and total resistance were calculated using the following formula:

$$
\begin{gathered}
E=\frac{1}{8} C_{S}\left(V-V_{\text {drop }}\right)^{2} \\
P=\frac{1}{2}\left(V-V_{\text {drop }}\right)\left(\frac{I}{2 m}\right) \\
C_{s}=2\left(\frac{I}{m}\right)\left(\frac{d t}{d V}\right) \\
R_{t}=\frac{V_{\text {drop }}}{I}
\end{gathered}
$$

where

$m$ is the mass of single electrode

$I$ is the current

$V$ is the maximum applied potential $(1 \mathrm{~V})$

$V_{\text {drop }}$ is the IR drop

$d V / d t$ is the rate of potential decline during the discharge (excluding IR drop)

$C_{s}$ is the specific capacitance of the material

$E$ is the specific energy density

$P$ is the specific power density

$R_{t}$ is the total resistance

The capacitive frequency response was calculated from the Electrochemical Impedance Spectroscopy (EIS) data using the following formula:

$$
\begin{gathered}
C=\frac{1}{j \omega Z}=\frac{1}{j \omega(\operatorname{Re}(Z)+j \operatorname{Im}(Z))} \\
|C|=\left[\{\operatorname{Re}(C)\}^{2}+\{\operatorname{Im}(C)\}^{2}\right]^{1 / 2} \\
a=2 \pi f
\end{gathered}
$$


The electrochemical impedance spectroscopy measurements were performed at $0 \mathrm{~V}$ using a sinusoidal signal of $10 \mathrm{mV}$ over the frequency range from $100 \mathrm{kHz}$ to $100 \mathrm{mHz}$. Following established procedures the total resistance is divided into two main components - (i) $R_{s}$ - series resistance comprising of electrolyte resistance, intrinsic resistance of carbon film and contact resistance at the interface of carbon film/current collector and (ii) $R_{i}$ - Ionic resistance, attributable to ion migration within the carbon film and carbon pores. The series resistance, $R_{s}$, is given by the first intersection point of the Nyquist spectrum in the high-frequency region. The ionic resistance, $R_{i}$, is the difference between total resistance $\left(R_{t}\right)$ and series resistance $\left(R_{S}\right)$.

\section{Results and Discussion}

\subsection{Physical Characterization of synthesized porous carbon materials}

The textural and physical characteristics of the various PCs are presented in Table 1 and Figure $2(a, b)$. There are three important things to note from the porosity data. First, PC 0-0-2 (produced through salt templating alone), has very high surface area arising from the presence of secondary micropores and mesopores with a size around $\sim 2 \mathrm{~nm}$. Second, PC 4-1-0 and PC 22-10 (produced through hard templating alone), have large pore volumes arising from the presence of large size mesopores $\sim 7 \mathrm{~nm}$ and $\sim 26 \mathrm{~nm}$ generated through their respective silica template. Third, PC 4-1-2 and PC 22-1-2 (produced through combined hard templating-salt templating) show both high surface areas and very high pore volumes. The high surface area arises from the presence of secondary micropores and mesopores around $2 \mathrm{~nm}$ generated through the carbon matrix formed around the salt $\left(\mathrm{ZnCl}_{2}\right)$ nanoclusters. The mesopores and macropores $(\sim 22 \mathrm{~nm}$ and $\sim 64 \mathrm{~nm}$ for PC 4-1-2 and PC 22-1-2 respectively) are produced through the removal of silica nanoparticle clusters. The silica nanoparticle clusters are formed as a result of the controlled aggregation of silica after addition of $\mathrm{ZnCl}_{2}$ to the glucose-silica suspension. Since the 
carbonization proceeds under solvent free conditions, no further phase segregation appears to take place, enabling the mesopores/macropores generated from silica etching to still retain a relatively sharp peak in their respective pore size distributions. The solution-free carbonization strategy prevents uncontrolled phase segregation of the hydrophilic silica nanoparticles within the carbonizing (and increasingly becoming hydrophobic carbon precursor matrix) and thus alleviates the need for using costly surfactants [58], fast stirring speeds and/or dilute carbon precursor concentrations [59]. In order to confirm this finding, another set of carbonization experiments were performed, where the glucose-colloidal silica-salt solution was directly subjected to carbonization without removing the solvent through the vacuum drying step. As can be seen in Figure 2 (c, d), the carbons produced show a very broad pore size distribution indicative of uncontrolled phase segregation, unlike the relatively sharp peak obtained for carbons produced from vacuum drying of glucose-colloidal silica-salt solution.

Table 1. Surface Area and Porosity Characteristics of the various synthesized PCs

\begin{tabular}{|c|c|c|c|c|}
\hline \multicolumn{2}{|c|}{ Synthesis Procedure } & Sample & BET Surface & $\mathrm{N}_{2}$ adsorption pore \\
\hline \multirow{5}{*}{$\begin{array}{l}\text { Vacuum } \\
\text { assisted } \\
\text { drying }\end{array}$} & Salt templating alone & PC $0-0-2$ & 2062 & 1.12 \\
\hline & \multirow{2}{*}{ Hard templating alone } & PC 4-1-0 & 1457 & 2.56 \\
\hline & & PC 22-1-0 & 979 & 2.23 \\
\hline & \multirow{2}{*}{$\begin{array}{l}\text { Combined salt templating- } \\
\text { hard templating }\end{array}$} & PC 4-1-2 & 2013 & 3.91 \\
\hline & & PC 22-1-2 & 2096 & 3.87 \\
\hline \multirow{4}{*}{$\begin{array}{l}\text { Heat } \\
\text { assisted } \\
\text { drying }\end{array}$} & \multirow{2}{*}{ Hard templating alone } & HePC 4-1-0 & 1257 & 3.19 \\
\hline & & HePC 22-1-0 & 865 & 2.83 \\
\hline & \multirow{2}{*}{$\begin{array}{l}\text { Combined salt templating- } \\
\text { hard templating }\end{array}$} & HePC 4-1-2 & 1954 & 4.34 \\
\hline & & HePC 22-1-2 & 1846 & 3.30 \\
\hline \multirow{4}{*}{\multicolumn{2}{|c|}{$\begin{array}{l}\text { Combined Hard Templating-Salt } \\
\text { Templating-Physical Activation }\end{array}$}} & PCP 4-1-2-10 & 1908 & 4.30 \\
\hline & & РCP 4-1-2-17 & 2517 & 4.26 \\
\hline & & PCP 4-1-2-25 & 2404 & 3.55 \\
\hline & & $\begin{array}{l}\text { PCP 22-1-2- } \\
17\end{array}$ & 2579 & 3.57 \\
\hline \multicolumn{2}{|c|}{$\begin{array}{l}\text { Combined hard templating-salt } \\
\text { templating low Temperature } \\
\text { carbonization }\left(450^{\circ} \mathrm{C}\right)\end{array}$} & PCL 22-1-2 & 2108 & 3.24 \\
\hline
\end{tabular}


carbons produced through heat assisted drying, PCP stands for porous carbons produced through combined hard templating-salt templating-physical activation, PCL stands for porous carbons produced at lower carbonization temperature $\left(450{ }^{\circ} \mathrm{C}\right)$.

For PC $x-y$-z-o(if used), $x$ represents size of silica nanoparticle, $y$ represents mass ratio of silica/glucose, $z$ represents mass ratio of $\mathrm{ZnCl}_{2} /$ glucose, of or the case of physically activated samples represent the flow rate $(\mathrm{ml} / \mathrm{min})$ of $\mathrm{CO}_{2}$.

The multi-modal porosity of carbons produced through the combined hard-salt templating, could translate in both high energy density and high retention capability when used as supercapacitor electrodes. High surface area typically leads to high energy density while the the presence of big mesopores ( $22 \mathrm{~nm}$ in case of PC 4-1-2) or macropores ( $\sim 64 \mathrm{~nm}$ in case of PC 22-1-2) could lead to high retention capability, since they could act as both electrolyte reservoirs and highways for efficient electrolyte transport.

a
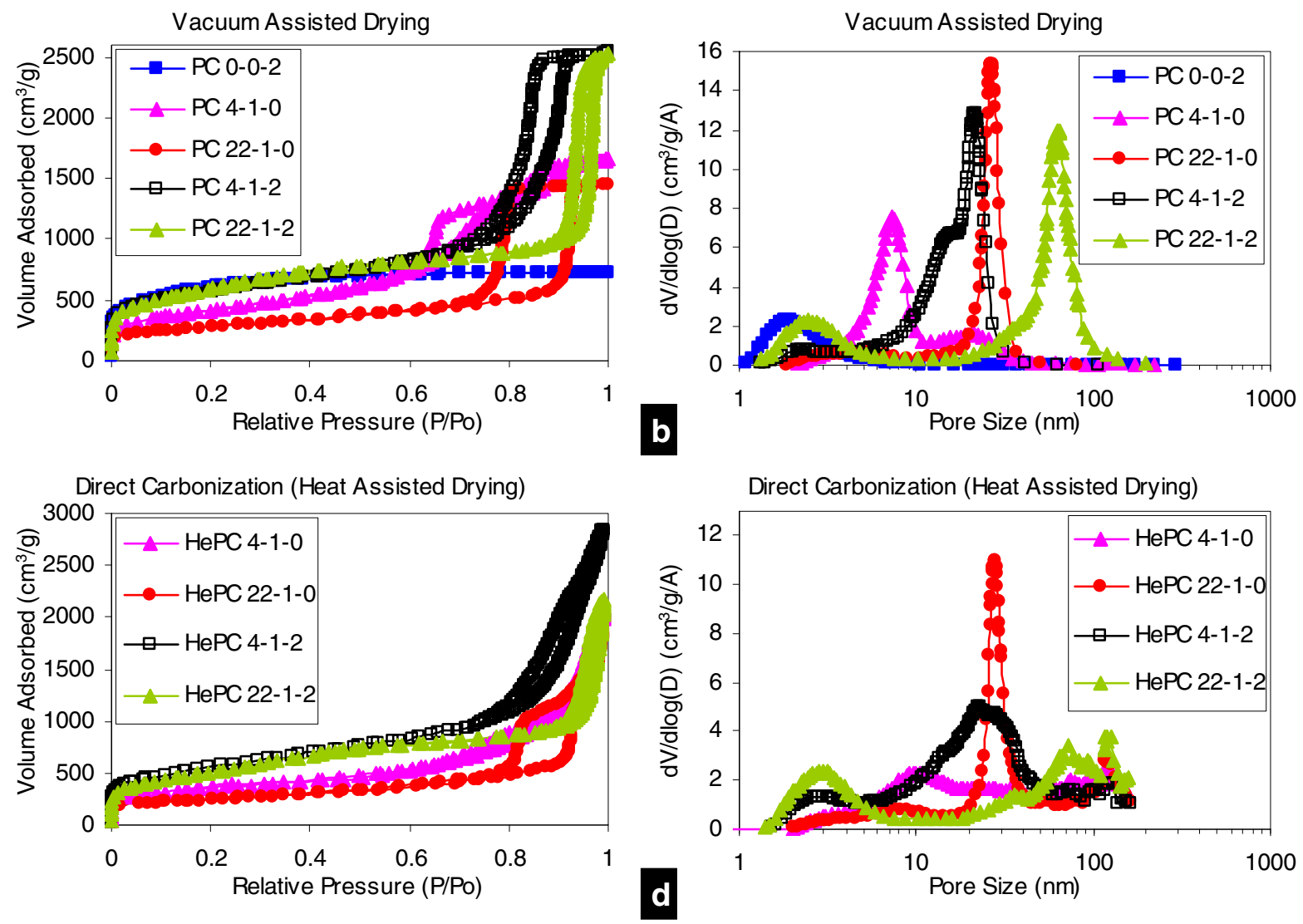

Figure 2. $\mathrm{N}_{2}$ sorption isotherm and pore size distribution for porous carbons synthesized through vacuum assisted drying $(\mathrm{a}, \mathrm{b})$ and direct carbonization (heat assisted drying) (c, d). 
Another important feature of our synthesis technique is that very high surface area multimodal carbons can be produced using a combination of salt templating-hard templating-physical activation. The only difference in the synthesis procedure in this case is that during the hold at $1000{ }^{\circ} \mathrm{C}$, the inert nitrogen gas is replaced with $\mathrm{CO}_{2} \cdot \mathrm{CO}_{2}$ activation is known to proceed through reactions between $\mathrm{CO}_{2}$ and the carbon matrix, thus leaving behind pores within the carbon matrix in the process [60]. The porosity (produced in-situ due to the boiling off of the $\mathrm{ZnCl}_{2}$ nanoclusters) facilitates the easy in-diffusion of $\mathrm{CO}_{2}$ to active sites and out-diffusion of reaction products [61]. The presence of $\mathrm{ZnCl}_{2}$ also ensures a higher degree of carbonization of the glucose-silica composite. Note that combined hard templating-physical activation (i.e. in the absence of $\mathrm{ZnCl}_{2}$ ), under same thermal conditions and $\mathrm{CO}_{2}$ flow rates, resulted in almost zero yield. The much lower yield is attributed to the lower degree of carbonization of silica-glucose composite, which leads to higher gasification rate upon reaction with $\mathrm{CO}_{2}$ [61]. The nitrogen sorption isotherms and pore size distribution results for samples produced through combined salt templating-hard templating-physical activation, with varying $\mathrm{CO}_{2}$ flow rates, are shown in Figure 3. For the combined hard templating-salt templating-physical activation, the degree of physical activation can be easily controlled by varying the $\mathrm{CO}_{2}$ flow rate. At high $\mathrm{CO}_{2}$ flow rates (e.g. $25 \mathrm{ml} / \mathrm{min}$ ), the carbon matrix between adjacent silica nanoparticles also seems to react with $\mathrm{CO}_{2}$, resulting in merger and enlargement of adjacent spherical mesopores, as can be seen in Figure 3 (b).

Another advantage of the combined salt templating-hard templating approach is that the carbonization can be achieved at a much lower temperature. The $\mathrm{ZnCl}_{2}$ salt, apart from acting as an in-situ template around which carbon matrix is formed, also acts as a dehydrating agent 
ensuring effective carbonization of glucose even at a low temperature, such as $450{ }^{\circ} \mathrm{C}$. In the absence of $\mathrm{ZnCl}_{2}$ salt, (i.e., when hard-templating alone is used), carbonization is incomplete at such low temperatures and the whole carbon matrix collapses upon etching of the silica template. This lack of porosity in low temperature carbonization of silica-glucose composites is highly evident from $\mathrm{N}_{2}$ porosimetry, as shown in Figure $4(\mathrm{a}, \mathrm{b})$. In contrast, a very high degree of porosity is obtained when a combination of salt-hard templating is used, in spite of the lower carbonization temperature. Such multi-modal low temperature (and thus highly energy efficient) carbonized samples could be highly useful candidates for water purification applications or as polymer impregnated supports for $\mathrm{CO}_{2}$ capture. Since the carbonization is carried out at a very low temperature, these samples have low electrical conductivity as compared to their respective high temperature $\left(1000{ }^{\circ} \mathrm{C}\right)$ carbonization counterparts, and, are thus, less attractive for electrochemical applications. 

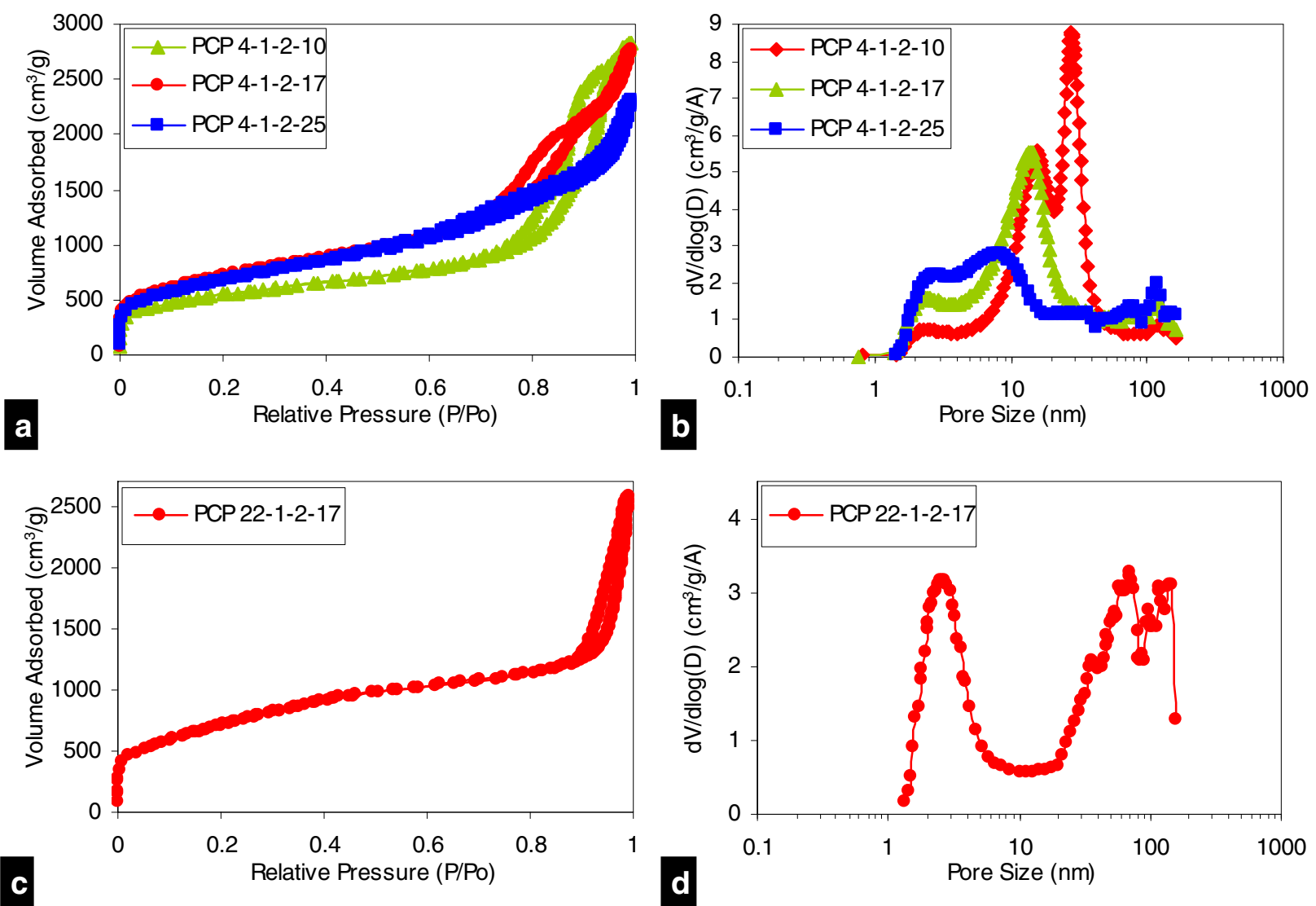

Figure 3. $\mathrm{N}_{2}$ sorption isotherm and pore size distribution for porous carbons synthesized using a combined salt templating-hard templating-physical activation approach. For the physical activation part, during the hold at $1000{ }^{\circ} \mathrm{C}$, the inert nitrogen gas is replaced with $\mathrm{CO}_{2}$. (a,b) show the effect of $\mathrm{CO}_{2}$ flow rate $(10,17,25 \mathrm{ml} / \mathrm{min})$ on the carbon porosity, (c,d) represents the sorption isotherm and pore size distribution for sample produced with $22 \mathrm{~nm}$ silica and activated at $\mathrm{CO}_{2}$ flow rate of $17 \mathrm{ml} / \mathrm{min}$.

a
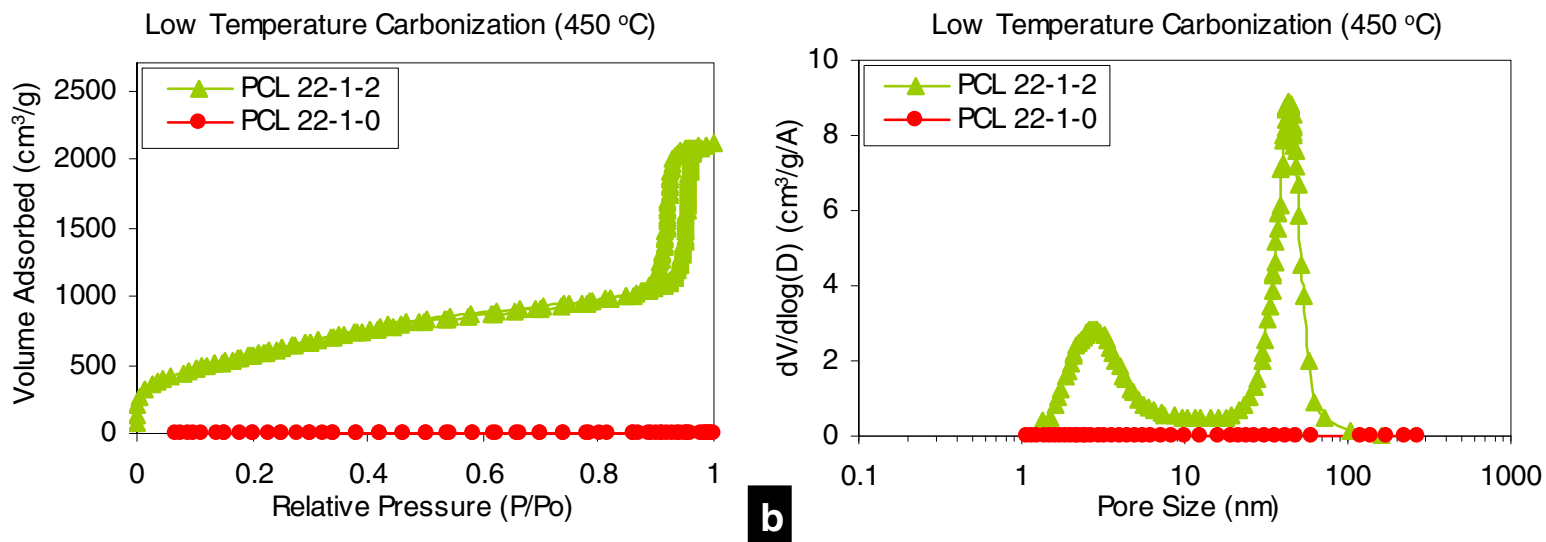

Figure 4. $\mathrm{N}_{2}$ sorption isotherm and pore size distribution for porous carbons synthesized through low temperature carbonization. The carbonization is carried out at $450{ }^{\circ} \mathrm{C}$, followed by etching with $1 \mathrm{M} \mathrm{HCl}$ to remove $\mathrm{ZnCl}_{2}$, followed by etching with $3 \mathrm{M} \mathrm{NaOH}$ to remove $\mathrm{SiO}_{2}$. 
Lastly we discuss one more advantage of this new synthesis technique: the possibility of using a combination of different metallic salts. In this situation one salt acts as a template to produce porous carbons, while the other can act as a precursor for the formation of metallic phyllosilicates embedded within the carbon matrix. One example of such a synthesis is demonstrated using a combination of $\mathrm{ZnCl}_{2}$ and a $\mathrm{Co}\left(\mathrm{NO}_{3}\right)_{2}$. The nitrogen sorption isotherm and the corresponding pore size distribution for the nanostructured cobalt phyllosilicate embedded in high surface area multi-modal carbon is shown in Figure $5(a, b)$. In spite of having high metal clay content $(\sim 27 \%$, calculated before and after $\mathrm{HCl}$ etching), the carbon has a very high surface area $\left(\sim 1527 \mathrm{~m}^{2} / \mathrm{g}\right)$ and pore volume $\left(\sim 3.63 \mathrm{~cm}^{3} / \mathrm{g}\right)$. The $\mathrm{ZnCl}_{2}$ salt, not only helps in generating high surface area by producing secondary micropores and mesopores, but because $\mathrm{ZnCl}_{2}$ boils off at the carbonization temperatures used in this synthesis, it eliminates the need for acid washing. It is important to avoid post-synthesis acid washing as it can also cause etching of the nanostrucutured phyllosilicate. The TEM image and the corresponding EDX spectrum are shown in Figure 6. The cobalt, silicon and oxygen mapping results confirm that the nanostructures in the TEM image are cobalt phyllosilicates. The presence of cobalt phyllosilicate within the carbon matrix imparts magnetic behavior to the composite material, as confirmed in Figure 6(f). Such metallic nanostructured clay embedded in multi-modal porous carbons could be used as magnetically-recoverable sorbents for water purification. 

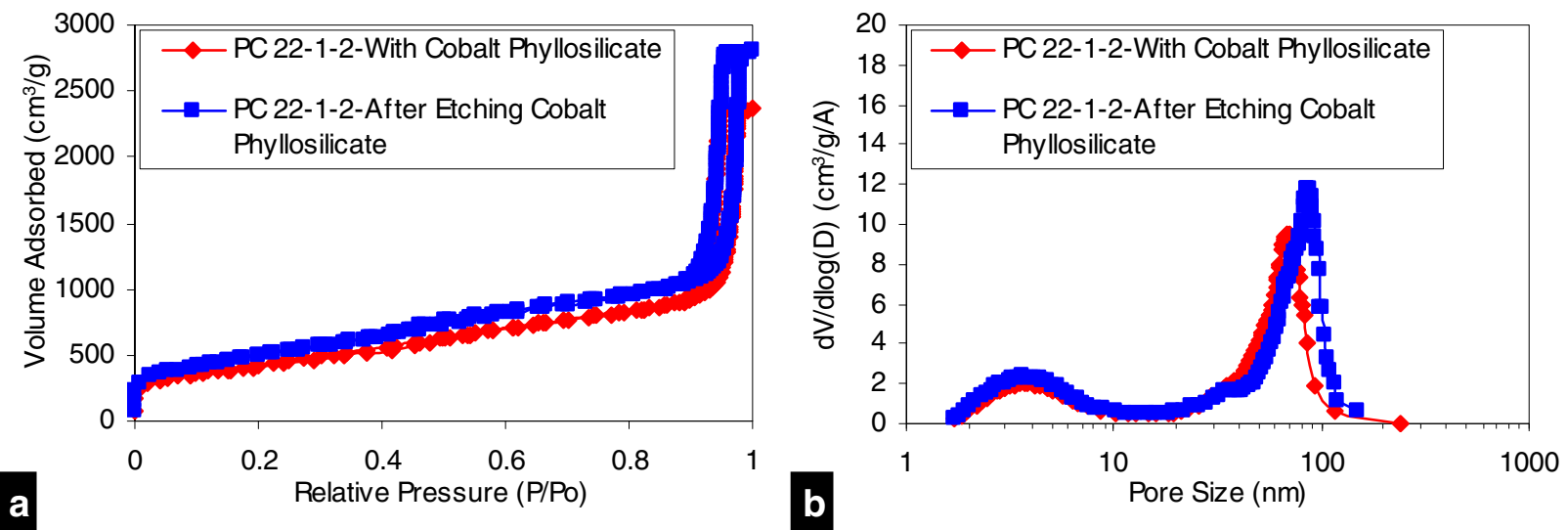

Figure 5. (a) $\mathrm{N}_{2}$ sorption isotherms and, (b) BJH pore size distributions - for (i) nanostructured cobalt phyllosilate embedded in bimodal porous carbons (surface area $-1527 \mathrm{~m}^{2} / \mathrm{g}$ and pore volume $-3.63 \mathrm{~cm}^{3} / \mathrm{g}$ ) and (ii) bimodal porous carbon after cobalt phyllosilicate etching (surface area $-1767 \mathrm{~m}^{2} / \mathrm{g}$ and pore volume $-4.32 \mathrm{~cm}^{3} / \mathrm{g}$ )

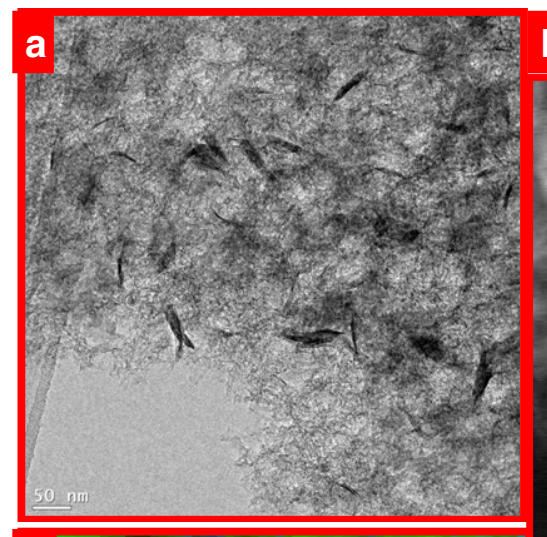

\section{b}
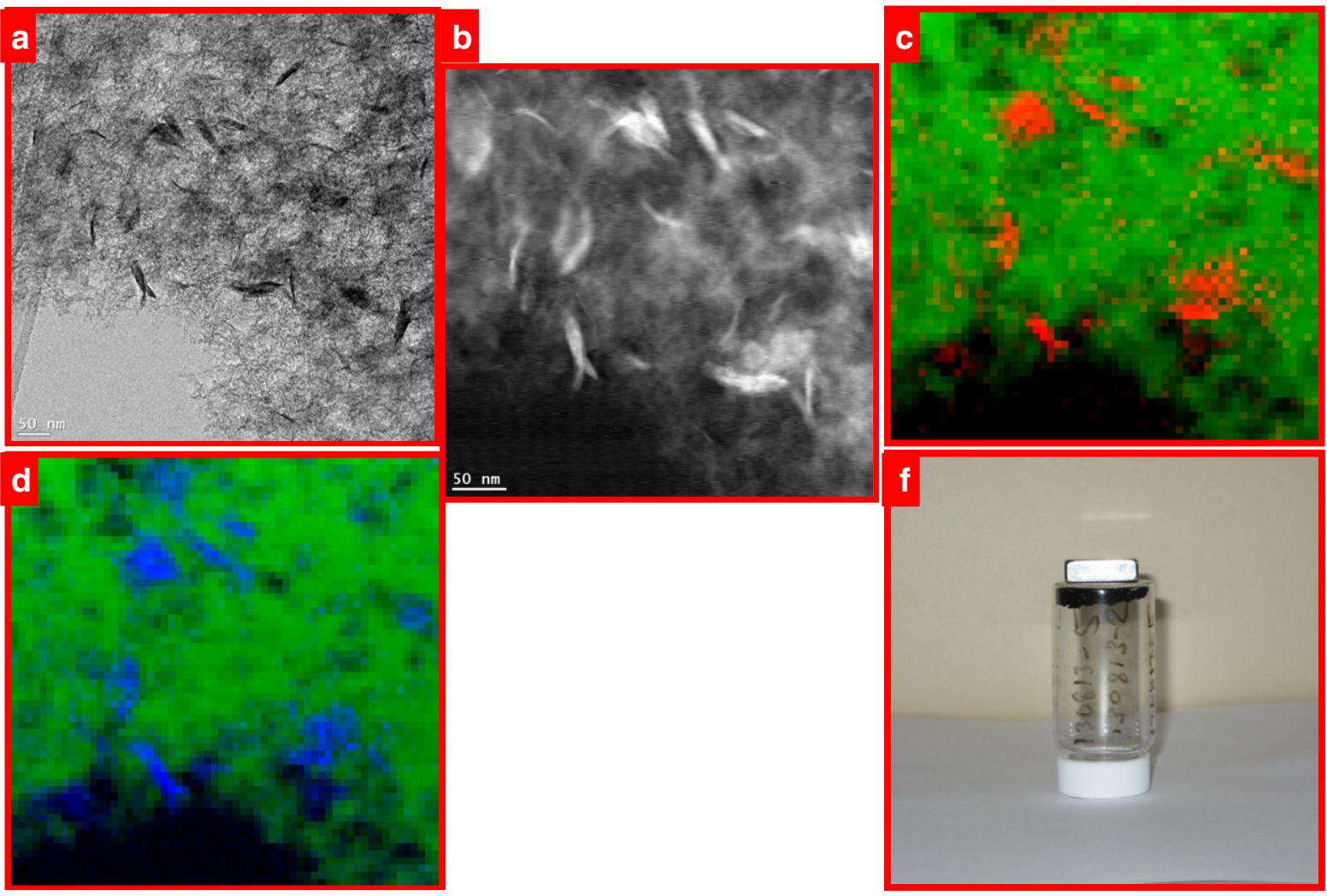

Figure 6. (a) TEM image for nanostructured cobalt phyllosilicate embedded in multi-modal porous carbon, (b) Selected area for EDX analysis, EDX mapping results for (c) cobalt (red), (d) silicon (blue), (e) oxygen (pink), where the green color represents the carbon matrix, (f) digital photograph confirming the magnetic nature of the material. 


\subsection{Electrochemical performance}

Detailed characterization measurements were carried out to investigate the interrelated effect of the carbon's porosity as well as the effect of pressure applied during electrode fabrication on the EDLC performance. We start by comparing the EDLC performance for each carbon as a function of increasing electrode fabrication pressure. For understanding the effects of porosity and electrode fabrication pressure, three different EDLC performance assessment measures are considered. First, we use the specific capacitance of the electrode as a function of increasing current density. Both, the absolute value of the specific capacitance as well as its retention as a function of increasing current density are considered. Second measure is the energy density and power density of the electrode, commonly plotted as a Ragone plot. Third is the evolution of the EIS spectra as a function of pressure applied during electrode fabrication. The contribution of different electrode components to the overall resistance as well as the capacitive frequency response for the various electrodes as a function of electrode fabrication pressure were also evaluated.

Figure 7 shows the variation of specific capacitance as a function of current density for PCs with different pore size distributions for varying pressures applied during electrode fabrication. There are three important things to note from Figure 7. First, for the lowest current density measured, i.e. $0.5 \mathrm{~A} / \mathrm{g}$, under various electrode pressing conditions, the specific capacitance increases with increasing electrode fabrication pressure mainly for carbons having microporosity and small size borderline mesopores produced from salt templating, i.e., PC 0-0-2, PC 22-1-2 and PC 4-1-2. For carbons having only large size mesopores, produced from hardtemplating alone, the capacitance at low current densities increases only marginally with 
increasing electrode fabrication pressure. These results can be rationalized as follows: low current densities imply slow charge-discharge conditions. And low fabrication pressure implies low electrolyte filling, which consequently increases with increased fabrication pressure, as suggested by previous studies $[11,12]$. Thus, at low current densities, in spite of the low electrolyte filling (at low electrode fabrication pressure), there is enough time for the electrolyte to diffuse in the mesopores. Thus, the capacitance improvement with increased electrolyte filling (with increased electrode fabrication pressure) is only marginal in the case of hard templated mesoporous carbons, as most of the mesopores are easily accessible through diffusion alone. On the other hand, for carbons with microporosity and small size mesopores, the diffusion within the micropores and small size mesopores is slow, even at the lowest current density tested, resulting in incomplete utilization of the available porosity. Thus, as electrolyte filling increases with increasing pressure, the diffusion length and time needed to access the micropores and small size mesopores decreases, thus resulting in enhanced capacitance. At high current densities or fast charge-discharge conditions, the electrolyte diffusion is not fast enough to warrant complete porosity utilization offered by even big size mesopores. Thus, the increased electrolyte filling leads to an increase in capacitance for all the carbons, associated with reduced diffusion lengths and timelines. Capacitance retention shown in Figure S3 (defined as the ratio of capacitance at any current density to that at lowest current density) also increases with increased electrolyte filling within the pores. However, for PC 0-0-2, containing only micropores and small size mesopores, although the capacitance retention increases with increasing electrode fabrication pressure, it only reaches a maximum value of 54\%. For all the other carbons containing mesopores from hard templating, capacitance retention in the order of $80 \%$ is achieved. The low capacitance retention for PC 0-0-2 implies that it may not be possible to completely fill the 
micropores and small mesopores, in contrast to previous reports [11]. This different extent of electrolyte filling within carbons with varying porosity while applying the same amount of pressure can also be explained by the fact that the applied pressure has to overcome both the capillary pressure, which is inversely proportional to the pore size, as well as the trapped air pressure [11]. Moreover, if complete or high-level of electrolyte filling was possible for micropores and small mesopores, then a much higher capacitance retention should be obtained at higher electrode fabrication pressures for PC $0-0-2$, just like in the case of mesoporous carbons (PC 4-1-0 and PC 22-1-0) and multi-modal carbons (PC 4-1-2 and PC 22-1-2). This is because if the electrolyte filled completely all the pores, then the ions would only need to migrate to the pore wall to form the double layer and thus capacitance retention should be independent of pore size, which is not the case.
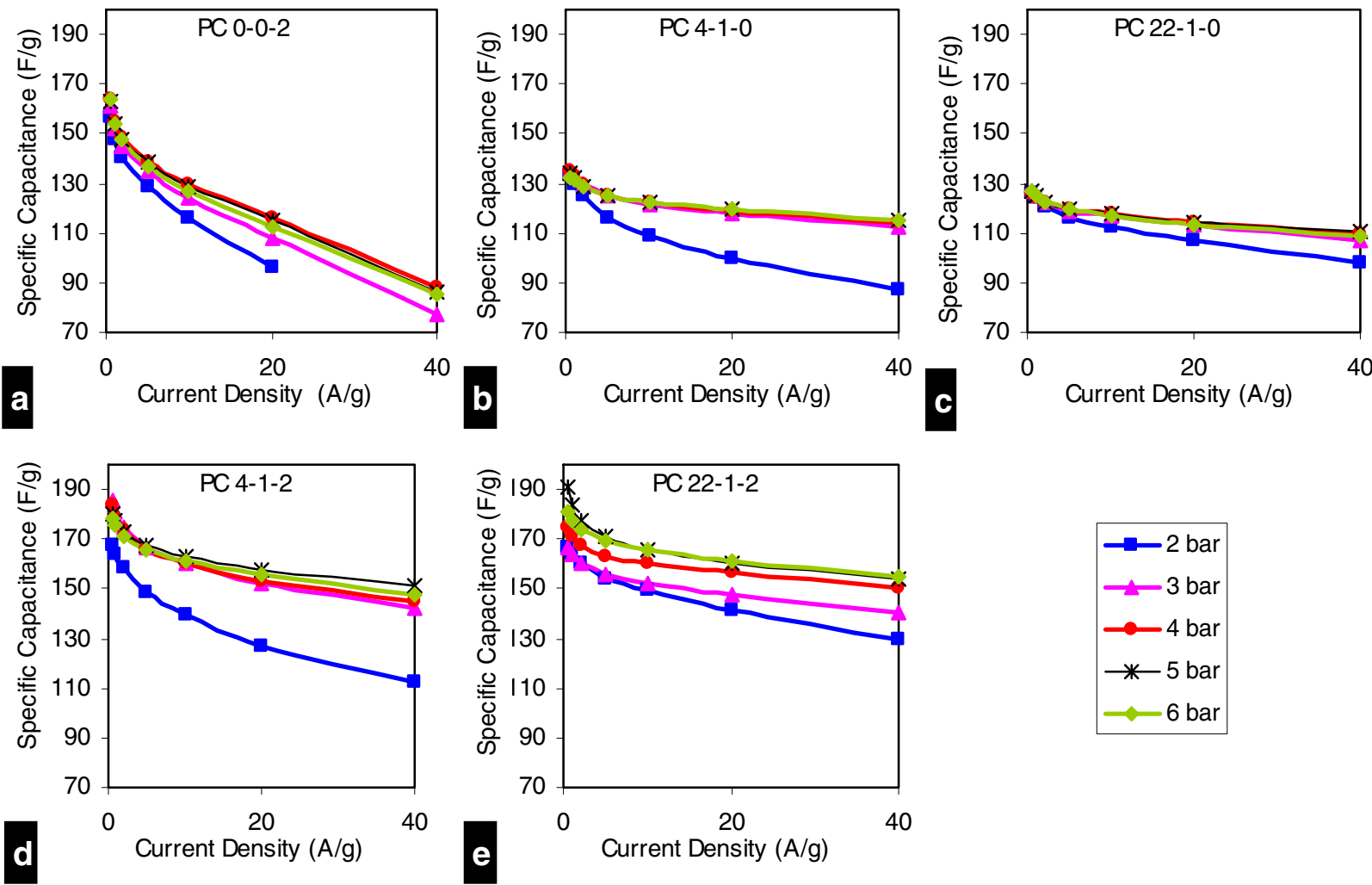
Figure 7. Specific capacitance as a function of current density for electrodes fabricated using different pressures in the presence of $1 \mathrm{M} \mathrm{H}_{2} \mathrm{SO}_{4}$ electrolyte.

Figure 8 shows the Ragone plot for the various PCs with different pore size distributions as a function of increasing pressure applied during electrode fabrication. There are two important things to note from Figure 8. First, the energy and power densities for the various carbons increase with increasing electrode fabrication pressure, reaching a maximum value at an optimum pressure before it starts falling. The energy density increases as a result of both - an increase in capacitance as well as a decrease in IR drop as a result of a decrease in resistance with increasing electrode fabrication pressure. The power density increases with increasing electrode fabrication pressure as a result of decrease in resistance. The existence of an optimum pressure beyond which the performance starts falling can be explained on the basis of collapse of big size pores beyond a certain electrode fabrication pressure[18]. Secondly, as can be seen in Figure S5, among the various PCs, at any electrode fabrication pressure, the multi-modal carbons, PC 22-1-2 and PC 4-1-2, prepared through combined hard-salt templating, provide the highest energy density for both high and low power applications. Comparing the salt templated carbon (PC 0-0-2) with hard templated ones (PC 4-1-0 and PC 22-1-0), the former shows high energy density for low-medium power applications, while the latter, despite their lower surface area, show high energy storage for high power applications. PC 0-0-2 has a micropore (and borderline mesopore) dominated pore size distribution, which as explained earlier, leads to only partial electrolyte filling, even with increasing electrode fabrication pressure. Thus, PC 0-0-2 has a higher ionic resistance associated with it, as confirmed in Figure 10c (vide infra), which results in higher IR loss and thus lower energy density (see equation 2) at high current densities. On the other hand, the hard-templated carbons (PC 4-1-0 and PC 22-1-0) have an abundance of larger 
mesopores, which become increasingly filled with the electrolyte as a function of electrode fabrication pressure. This feature leads to low ionic resistance and thus lower IR drop and highenergy storage even at high current densities. We conclude that carbons produced via hard/salt templating combine the high surface area from salt templating and big size mesopores (or macropores) from hard templating result in high energy storage at both low and high current densities.
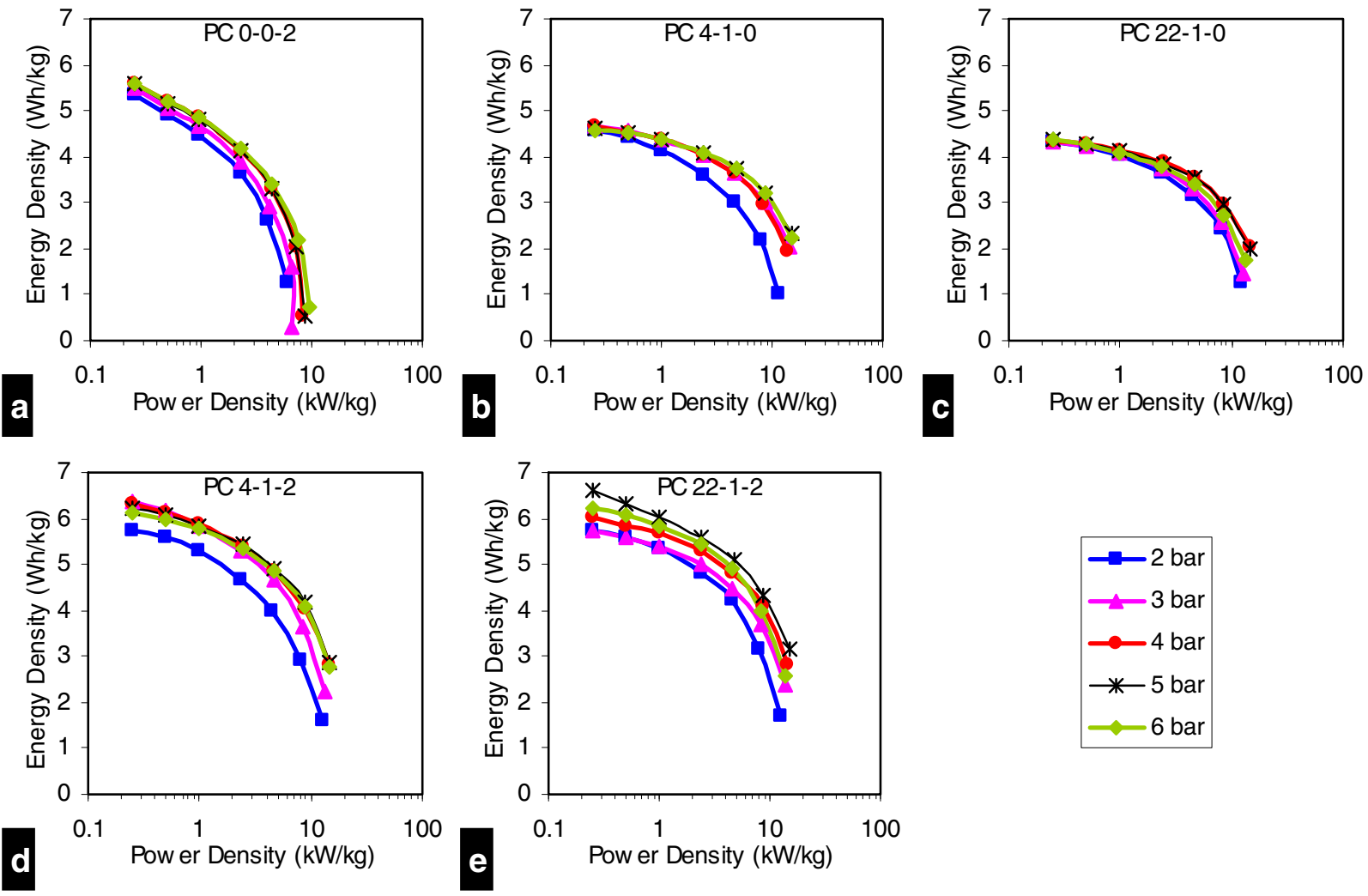

Figure 8. Ragone plots for electrodes fabricated at different pressures in the presence of $1 \mathrm{M}$ $\mathrm{H}_{2} \mathrm{SO}_{4}$.

The EIS results are presented in Figure 9. The deconvolution of the total resistance into different components is presented in Figure 10. There are two important things to note from the resistance break-up plot. First, the total resistance is highest for the salt-templated carbon, PC 0$0-2$, containing only secondary micropores and small mesopores, with the bulk of the contribution coming from ion migration resistance. On the other hand, the hard-templated 
carbons having relatively larger mesopores show low ion migration resistance. These results suggest that the extent of electrolyte filling decreases with decreasing pore size. Second, the ion migration resistance decreases with increasing pressure. Both findings could be attributed to the increased filling of electrolyte within the pores as a result of applying increasing pressure during electrode fabrication. Increased electrolyte filling results in reduced diffusion length and time required for ion migration to the pore wall for forming the electrochemical double layer, thus resulting in low ionic resistance. Apart from analyzing the resistive behavior, the impedance spectra can also be used to determine the capacitive response as a function of modulation frequency. A sample normalized capacitive frequency response (calculated using equations 4, 5, 6) for an electrode made with PC 4-1-0 is shown in Figure S7. The frequency at which the normalized capacitance becomes half, for the various carbon electrodes manufactured at different fabrication pressures, is given in Figure 10(d). As can be seen in Figure 10(d), the frequency corresponding to $50 \%$ capacitance retention, increases with increasing electrode fabrication pressure, as a result of higher utilization of the available area in line with the results from the GCD measurements. Also the frequency values is highest for hard-templated carbons having big mesopores and lowest for salt-templated carbon having only secondary micropores and small size/borderline mesopores. 

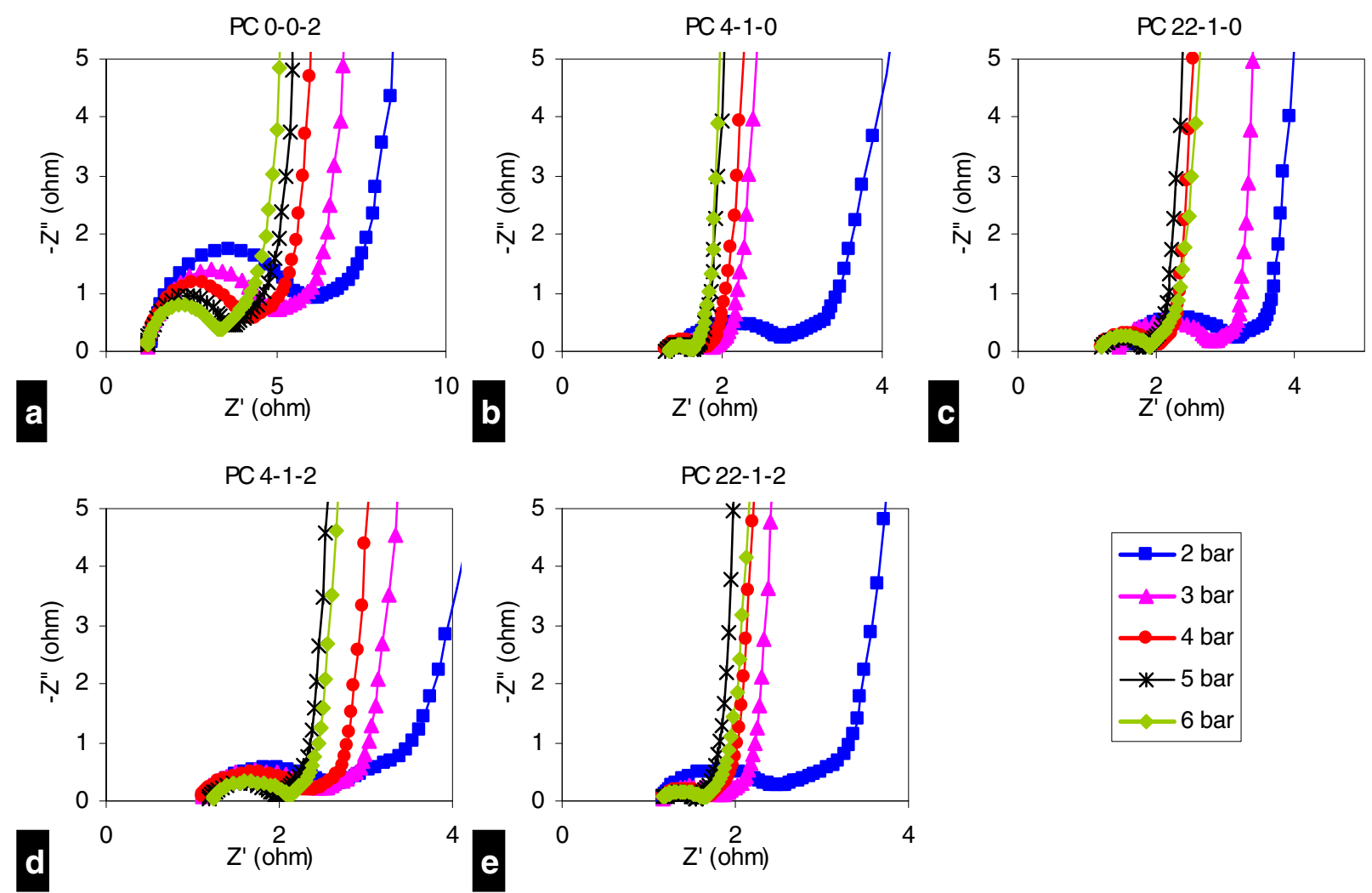

Figure 9. Electrochemical impedance spectroscopy for electrodes fabricated at different pressures in $1 \mathrm{M} \mathrm{H}_{2} \mathrm{SO}_{4}$.

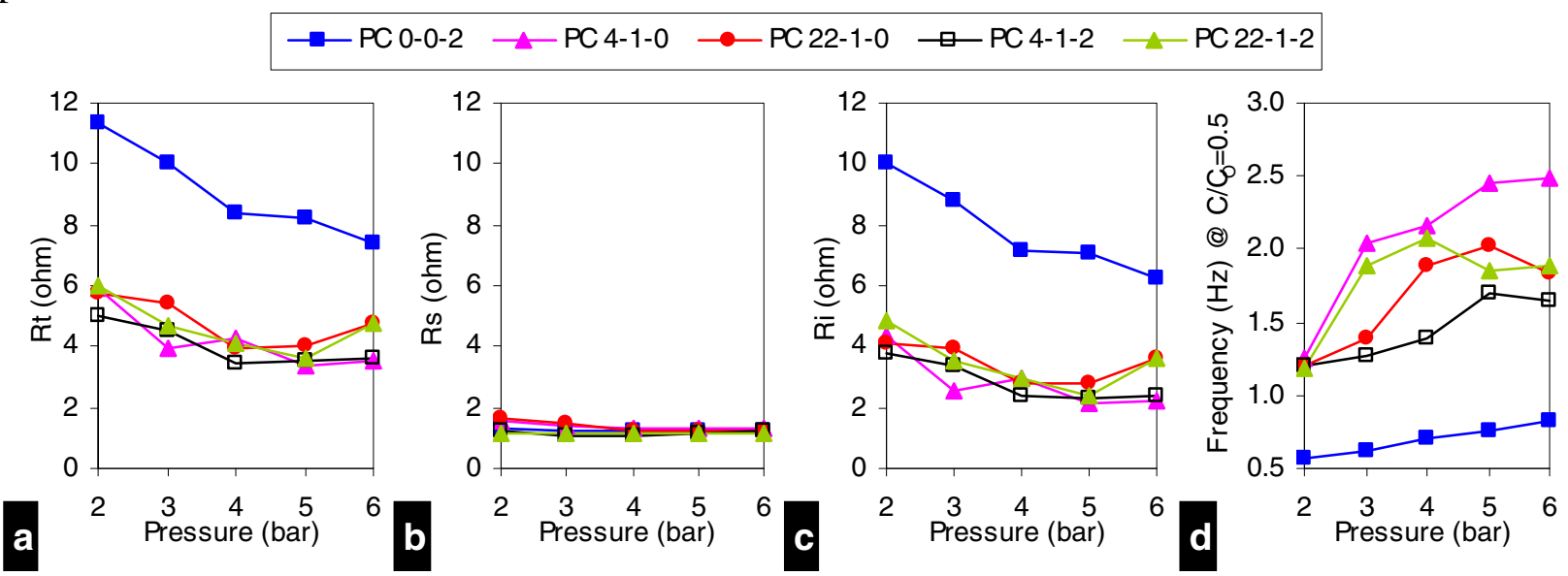

Figure 10. Pressure dependent variation of (a) total resistance (Rt), (b) series resistance (Rs), (c) ionic resistance $(\mathrm{Ri}),(\mathrm{d})$ capacitive frequency response (frequency corresponding to $50 \%$ capacitance retention, calculated from the EIS measurements.

As demonstrated above, superior EDLC performance can be obtained by pressing the electrodes in the presence of the electrolyte. It is important to note that two things can happen simultaneously as a result of applying pressure in the presence of electrolyte. First, the carbon 
particles can come together as a result of compression, thus reducing the contact resistance [13]. Second, the electrolyte can fill the pores, thus reducing the ion migration resistance [11]. In order to understand which resistance gets affected the most, two more set of tests were performed: (i) pressing in the presence of MilliQ water, and (ii) pressing under dry conditions. Performance enhancement for pressing under dry conditions can be safely ascribed to reduction in contact resistance only. On the other hand, pressing in the presence of MilliQ water, is expected to decrease the ionic resistance. This decrease is because, when the water filled electrodes come in contact with the electrolyte solution, the ion diffusion into the water filled pores is enhanced due to concentration gradient. Never the less, the decrease in resistance as a result of compression in MilliQ water case should be lower than when pressed in the presence of the electrolyte. Thus, the performance of pressing in MilliQ water is expected to be intermediate between the dry pressing and pressing in the presence of the electrolyte.

The results (Ragone plot, capacitance measurement, EIS plot, resistance composition and capacitive frequency response) for all the three pressing conditions - (i) pressing in presence of electrolyte, (ii) pressing in presence of MilliQ water and (iii) pressing in dry conditions are presented in Figure 11. The tests were conducted for the best performing carbon, PC 22-1-2. The EDLC performance for the three different testing conditions at their respective optimum pressing pressure follows the order - (electrolyte pressing $)>($ MilliQ water pressing $)>($ dry pressing $)$. The electrodes prepared by the dry pressing procedure, exhibit both low capacitance as well as high resistance, leading to poor energy and power density. The break-up of resistance into different components suggests that $R_{s}$ is the same for both electrolyte pressing and MilliQ water pressing case. Whereas the $R_{i}$ is slightly lower for the electrolyte pressing case compared to the MilliQ water pressing case. This lowered $R_{i}$ results in superior EDLC performance, likely due to 
the presence of ions within the carbon particles and carbon pores when electrodes are fabricated under pressure in the presence of the electrolyte. For electrodes fabricated under pressure in the presence of MilliQ water, the ions need to diffuse through the solvent present between the carbon particles and within the carbon pores. The $R_{i}$ for electrodes fabricated in the presence of electrolyte as well as the MilliQ water is much lower compared to the dry fabrication method. This can be explained on the basis of diminished ion diffusion through the compacted carbon particles and within empty carbon pores. 

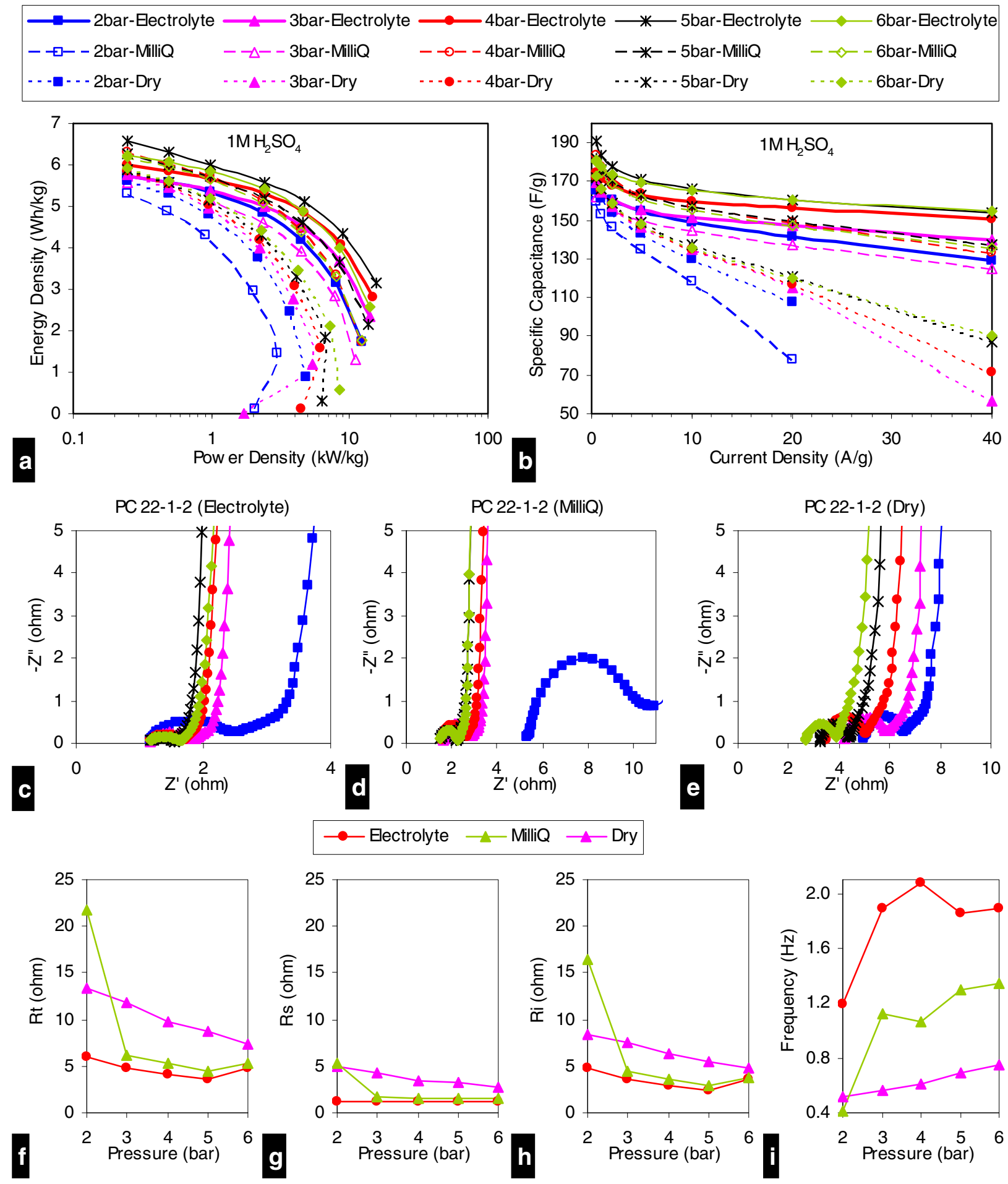

Figure 11. (a) Ragone plot, (b) specific capacitance, (c, d, e) EIS spectrum, (f) total resistance $(\mathrm{Rt}),(\mathrm{g})$ series resistance $(\mathrm{Rs}),(\mathrm{h})$ ionic resistance $(\mathrm{Ri})$, (i) capacitive frequency response (frequency corresponding to $50 \%$ capacitance retention, calculated from the EIS measurements), for electrodes fabricated under pressure in the presence of $\mathrm{H}_{2} \mathrm{SO}_{4}$ electrolyte, MilliQ and under dry conditions. 


\section{Conclusion}

In summary, we have demonstrated a new approach, based on a combination of salt templating and hard templating for producing bimodal micropore-mesopore dominated carbons. The synthesized bimodal carbons have both high surface areas arising from the presence of secondary micropores and small size mesopores produced from salt templating, and high pore volumes arising from large size mesopores produced from hard templating. The synthesis technique is highly versatile and offers the ability to produce a range of porous carbons by using different combinations of salts and hard templates. In addition, the use of $\mathrm{ZnCl}_{2}$ as the salt template also makes low temperature $\left(450^{\circ} \mathrm{C}\right)$ carbonization feasible because of the hygroscopic nature of $\mathrm{ZnCl}_{2}$. The technique can also be easily combined with physical activation for producing very high surface area $\left(\sim 2600 \mathrm{~m}^{2} / \mathrm{g}\right)$ multi-modal porous carbons through single-step carbonization alone. The synthesized (i) microporous, (ii) mesoporous, (iii) bimodal (microporemesopore dominated) carbons produced through salt templating alone, hard templating alone and combined salt-hard templating respectively, were used as electrode to compare the simultaneous effects of porosity and pressure applied during electrode fabrication on EDLC performance. The combined salt-hard templated carbons exhibited highest energy storage for both low and high power applications. The effect of pressure applied during electrode fabrication on EDLC performance was more favorable for carbons containing hard templated mesopores. This result was attributed to increased electrolyte filling within the hard-templated mesopores as compared to micropores. GCD and EIS measurements carried out for three different configurations (i) pressing in the presence of electrolyte, (ii) pressing in the presence of MilliQ water, (iii) dry pressing, confirmed that reduced ion migration resistance (because of ion filling within the 
pores) followed by reduced contact resistance (because of electrode compression), were responsible for the improved EDLC performance upon pressing.

\section{Acknowledgements:}

This work was supported in part by award no. KUS-C1-018-02 made by King Abdullah University of Science and Technology (KAUST), by the Energy Materials Center at Cornell (EMC2) an Energy Frontiers Research Center funded by the US Department of Energy and by the National Science Foundation (NSF) Grassroots GK-12 program (Award no. DGE 1045513).

The authors thank Dr. Nini Wei and Dr. Qingxiao Wang (KAUST Imaging and Characterization Core Lab) for their help with the TEM and EDX investigation.

\section{References:}

[1] Sillars FB, Fletcher SI, Mirzaeian M, Hall PJ. Effect of activated carbon xerogel pore size on the capacitance performance of ionic liquid electrolytes. Energy \& Environmental Science. 2011;4(3):695-706.

[2] Zhang L, Yang X, Zhang F, Long G, Zhang T, Leng K, et al. Controlling the Effective Surface Area and Pore Size Distribution of sp2 Carbon Materials and Their Impact on the Capacitance Performance of These Materials. J Am Chem Soc. 2013;135(15):5921-9.

[3] Vaquero S, Diaz R, Anderson M, Palma J, Marcilla R. Insights into the influence of pore size distribution and surface functionalities in the behaviour of carbon supercapacitors. Electrochim Acta. 2012;86:241-7.

[4] Jaramillo MM, Mendoza A, Vaquero S, Anderson M, Palma J, Marcilla R. Role of textural properties and surface functionalities of selected carbons on the electrochemical behaviour of ionic liquid based-supercapacitors. RSC Advances. 2012;2(22):8439-46.

[5] Estevez L, Dua R, Bhandari N, Ramanujapuram A, Wang P, Giannelis EP. A facile approach for the synthesis of monolithic hierarchical porous carbons - high performance materials for amine based CO2 capture and supercapacitor electrode. Energy \& Environmental Science. 2013;6(6):1785-90.

[6] Zhou D-D, Du Y-J, Song Y-F, Wang Y-G, Wang C-X, Xia Y-Y. Ordered hierarchical mesoporous/microporous carbon with optimized pore structure for supercapacitors. Journal of Materials Chemistry A. 2013;1(4):1192-200. 
[7] Liu HJ, Wang J, Wang CX, Xia YY. Ordered Hierarchical Mesoporous/Microporous Carbon Derived from Mesoporous Titanium-Carbide/Carbon Composites and its Electrochemical Performance in Supercapacitor. Advanced Energy Materials. 2011;1(6):1101-8.

[8] Fang B, Kim JH, Kim M-S, Bonakdarpour A, Lam A, Wilkinson DP, et al. Fabrication of hollow core carbon spheres with hierarchical nanoarchitecture for ultrahigh electrical charge storage. J Mater Chem. 2012;22(36):19031-8.

[9] Wang DW, Li F, Liu M, Lu GQ, Cheng HM. 3D Aperiodic Hierarchical Porous Graphitic Carbon Material for High-Rate Electrochemical Capacitive Energy Storage. Angew Chem. 2008;120(2):379-82.

[10] Dhawale DS, Benzigar MR, Wahab MA, Anand C, Varghese S, Balasubramanian VV, et al. Fine tuning of the supercapacitive performance of nanoporous carbon electrodes with different pore diameters. Electrochim Acta. 2012;77(0):256-61.

[11] Masarapu C, Wang L-P, Li X, Wei B. Tailoring Electrode/Electrolyte Interfacial Properties in Flexible Supercapacitors by Applying Pressure. Advanced Energy Materials. 2012;2(5):546-52.

[12] Li X, Rong J, Wei B. Electrochemical Behavior of Single-Walled Carbon Nanotube Supercapacitors under Compressive Stress. ACS Nano. 2010;4(10):6039-49.

[13] Dsoke S, Tian X, Täubert C, Schlüter S, Wohlfahrt-Mehrens M. Strategies to reduce the resistance sources on Electrochemical Double Layer Capacitor electrodes. J Power Sources. 2013;238(0):422-9.

[14] Lei C, Markoulidis F, Ashitaka Z, Lekakou C. Reduction of porous carbon/Al contact resistance for an electric double-layer capacitor (EDLC). Electrochim Acta. 2013;92(0):183-7. [15] Portet C, Taberna PL, Simon P, Laberty-Robert C. Modification of Al current collector surface by sol-gel deposit for carbon-carbon supercapacitor applications. Electrochim Acta. 2004;49(6):905-12.

[16] Bonnefoi L, Simon P, Fauvarque JF, Sarrazin C, Dugast A. Electrode optimisation for carbon power supercapacitors. J Power Sources. 1999;79(1):37-42.

[17] Huang C-W, Hsieh C-T, Kuo P-L, Teng H. Electric double layer capacitors based on a composite electrode of activated mesophase pitch and carbon nanotubes. J Mater Chem. 2012;22(15):7314-22.

[18] Murali S, Quarles N, Zhang LL, Potts JR, Tan Z, Lu Y, et al. Volumetric capacitance of compressed activated microwave-expanded graphite oxide (a-MEGO) electrodes. Nano Energy. 2013;2(5):764-8.

[19] Zhong H, Xu F, Li Z, Fu R, Wu D. High-energy supercapacitors based on hierarchical porous carbon with an ultrahigh ion-accessible surface area in ionic liquid electrolytes.

Nanoscale. 2013;5(11):4678-82.

[20] Dutta S, Bhaumik A, Wu KCW. Hierarchically porous carbon derived from polymers and biomass: effect of interconnected pores on energy applications. Energy \& Environmental Science. 2014.

[21] Wang Q, Yan J, Wang Y, Wei T, Zhang M, Jing X, et al. Three-dimensional flower-like and hierarchical porous carbon materials as high-rate performance electrodes for supercapacitors. Carbon. 2014;67(0):119-27.

[22] Liu C, Li F, Ma L-P, Cheng H-M. Advanced Materials for Energy Storage. Adv Mater. 2010;22(8):E28-E62.

[23] Enterria M, Castro-Muniz A, Suarez-Garcia F, Martinez-Alonso A, Tascon JMD, Kyotani T. Effects of the mesostructural order on the electrochemical performance of 
hierarchical micro-mesoporous carbons. Journal of Materials Chemistry A. 2014;2(30):1202330.

[24] Chen Z, Wen J, Yan C, Rice L, Sohn H, Shen M, et al. High-Performance

Supercapacitors Based on Hierarchically Porous Graphite Particles. Advanced Energy Materials. 2011;1(4):551-6.

[25] Fernandez J, Tennison S, Kozynchenko O, Rubiera F, Stoeckli F, Centeno T. Effect of mesoporosity on specific capacitance of carbons. Carbon. 2009;47(6):1598-604.

[26] Sevilla M, Alvarez S, Centeno TA, Fuertes AB, Stoeckli F. Performance of templated mesoporous carbons in supercapacitors. Electrochim Acta. 2007;52(9):3207-15.

[27] Hall PJ, Mirzaeian M, Fletcher SI, Sillars FB, Rennie AJR, Shitta-Bey GO, et al. Energy storage in electrochemical capacitors: designing functional materials to improve performance. Energy \& Environmental Science. 2010;3(9):1238-51.

[28] Carriazo D, Pico F, Gutierrez MC, Rubio F, Rojo JM, del Monte F. Block-Copolymer assisted synthesis of hierarchical carbon monoliths suitable as supercapacitor electrodes. J Mater Chem. 2010;20(4):773-80.

[29] Wei SC, Zhang H, Huang YQ, Wang WK, Xia YZ, Yu ZB. Pig bone derived hierarchical porous carbon and its enhanced cycling performance of lithium-sulfur batteries. Energy \& Environmental Science. 2011;4(3):736-40.

[30] Li Y, Li Z, Shen PK. Simultaneous Formation of Ultrahigh Surface Area and ThreeDimensional Hierarchical Porous Graphene-Like Networks for Fast and Highly Stable Supercapacitors. Adv Mater. 2013;25(17):2474-80.

[31] Hamad JZ, Dua R, Kurniasari N, Kennedy MD, Wang P, Amy GL. Irreversible membrane fouling abatement through pre-deposited layer of hierarchical porous carbons. Water Res. 2014;65(0):245-56.

[32] Xu J, Zhang R, Wu C, Zhao Y, Ye X, Ge S. Electrochemical performance of graphitized carbide-derived-carbon with hierarchical micro- and meso-pores in alkaline electrolyte. Carbon. 2014;74(0):226-36.

[33] Mun Y, Jo C, Hyeon T, Lee J, Ha K-S, Jun K-W, et al. Simple synthesis of hierarchically structured partially graphitized carbon by emulsion/block-copolymer co-template method for high power supercapacitors. Carbon. 2013;64(0):391-402.

[34] Yu L, Brun N, Sakaushi K, Eckert J, Titirici MM. Hydrothermal nanocasting: Synthesis of hierarchically porous carbon monoliths and their application in lithium-sulfur batteries. Carbon. 2013;61(0):245-53.

[35] Ning R, Ge C, Liu Q, Tian J, Asiri AM, Alamry KA, et al. Hierarchically porous Ndoped carbon nanoflakes: Large-scale facile synthesis and application as an oxygen reduction reaction electrocatalyst with high activity. Carbon. 2014;78(0):60-9.

[36] Wang D-W, Zhou G, Li F, Wu K-H, Lu GQ, Cheng H-M, et al. A microporousmesoporous carbon with graphitic structure for a high-rate stable sulfur cathode in carbonate solvent-based Li-S batteries. PCCP. 2012;14(24):8703-10.

[37] Yang SJ, Kim T, Im JH, Kim YS, Lee K, Jung H, et al. MOF-Derived Hierarchically Porous Carbon with Exceptional Porosity and Hydrogen Storage Capacity. Chem Mater. 2012;24(3):464-70.

[38] Nishihara H, Kyotani T. Templated Nanocarbons for Energy Storage. Adv Mater. 2012;24(33):4473-98.

[39] Enterría M, Suárez-García F, Martínez-Alonso A, Tascón JMD. One-pot endo/exotemplating of hierarchical micro-mesoporous carbons. Carbon. 2013;54(0):365-77. 
[40] Kim K, Choi M, Ryoo R. Ethanol-based synthesis of hierarchically porous carbon using nanocrystalline beta zeolite template for high-rate electrical double layer capacitor. Carbon. 2013;60(0):175-85.

[41] Zhang J, Jin L, Cheng J, Hu H. Hierarchical porous carbons prepared from direct coal liquefaction residue and coal for supercapacitor electrodes. Carbon. 2013;55(0):221-32.

[42] Liu R-L, Ji W-J, He T, Zhang Z-Q, Zhang J, Dang F-Q. Fabrication of nitrogen-doped hierarchically porous carbons through a hybrid dual-template route for $\mathrm{CO} 2$ capture and haemoperfusion. Carbon. 2014;76(0):84-95.

[43] Yang SJ, Kim T, Lee K, Kim YS, Yoon J, Park CR. Solvent evaporation mediated preparation of hierarchically porous metal organic framework-derived carbon with controllable and accessible large-scale porosity. Carbon. 2014;71(0):294-302.

[44] Han S, Sohn K, Hyeon T. Fabrication of New Nanoporous Carbons through Silica Templates and Their Application to the Adsorption of Bulky Dyes. Chem Mater. 2000;12(11):3337-41.

[45] Górka J, Jaroniec M. Hierarchically porous phenolic resin-based carbons obtained by block copolymer-colloidal silica templating and post-synthesis activation with carbon dioxide and water vapor. Carbon. 2011;49(1):154-60.

[46] Lv Y, Zhang F, Dou Y, Zhai Y, Wang J, Liu H, et al. A comprehensive study on KOH activation of ordered mesoporous carbons and their supercapacitor application. J Mater Chem. 2012;22(1):93-9.

[47] Hao P, Zhao Z, Tian J, Li H, Sang Y, Yu G, et al. Hierarchical Porous Carbon Aerogel Derived from Bagasse for High Performance Supercapacitor Electrode. Nanoscale. 2014. [48] Enterría M, Suárez-García F, Martínez-Alonso A, Tascón JMD. Synthesis of ordered micro-mesoporous carbons by activation of SBA-15 carbon replicas. Microporous Mesoporous Mater. 2012;151(0):390-6.

[49] Enterría M, Suárez-García F, Martínez-Alonso A, Tascón JMD. Avoiding structure degradation during activation of ordered mesoporous carbons. Carbon. 2012;50(10):3826-35. [50] Qie L, Chen W, Xu H, Xiong X, Jiang Y, Zou F, et al. Synthesis of functionalized 3D hierarchical porous carbon for high-performance supercapacitors. Energy \& Environmental Science. 2013;6(8):2497-504.

[51] Biswal M, Banerjee A, Deo M, Ogale S. From dead leaves to high energy density supercapacitors. Energy \& Environmental Science. 2013;6(4):1249-59.

[52] He X, Li R, Qiu J, Xie K, Ling P, Yu M, et al. Synthesis of mesoporous carbons for supercapacitors from coal tar pitch by coupling microwave-assisted $\mathrm{KOH}$ activation with a $\mathrm{MgO}$ template. Carbon. 2012;50(13):4911-21.

[53] Fechler N, Fellinger T-P, Antonietti M. "Salt Templating": A Simple and Sustainable Pathway toward Highly Porous Functional Carbons from Ionic Liquids. Adv Mater.

2013;25(1):75-9.

[54] Liu X, Antonietti M. Moderating Black Powder Chemistry for the Synthesis of Doped and Highly Porous Graphene Nanoplatelets and Their Use in Electrocatalysis. Adv Mater. 2013;25(43):6284-90.

[55] Liu X, Antonietti M. Molten salt activation for synthesis of porous carbon nanostructures and carbon sheets. Carbon. 2014(0).

[56] Fechler N, Wohlgemuth S-A, Jaker P, Antonietti M. Salt and sugar: direct synthesis of high surface area carbon materials at low temperatures via hydrothermal carbonization of glucose under hypersaline conditions. Journal of Materials Chemistry A. 2013;1(33):9418-21. 
[57] Liu X, Giordano C, Antonietti M. A Facile Molten-Salt Route to Graphene Synthesis. Small. 2014;10(1):193-200.

[58] Han S, Hyeon T. Simple silica-particle template synthesis of mesoporous carbons. Chem Commun. 1999(19):1955-6.

[59] Lee HI, Stucky GD, Kim JH, Pak C, Chang H, Kim JM. Spontaneous Phase Separation Mediated Synthesis of 3D Mesoporous Carbon with Controllable Cage and Window Size. Adv Mater. 2011;23(20):2357-61.

[60] Marsh H, Rodríguez-Reinoso F. Activated Carbon. Oxford: Elsevier Science Ltd; 2006. [61] Rodríguez-Reinoso F, Pastor AC, Marsh H, Martínez MA. Preparation of activated carbon cloths from viscous rayon. Part II: physical activation processes. Carbon. 2000;38(3):37995. 